\title{
Heterotopic pancreas in the stomach: A case report and literature review
}

\author{
Grigorios Christodoulidis, Dimitris Zacharoulis, Sotiris Barbanis, Emmanuel Katsogridakis, Konstantine Hatzitheofilou
}

Grigorios Christodoulidis, Dimitris Zacharoulis, Sotiris Barbanis, Emmanuel Katsogridakis, Konstantine Hatzi-theofilou, Department of Surgery, University Hospital of Larissa, Larissa 41221, Greece

Correspondence to: Grigorios Christodoulidis, MD, Department of Surgery, University Hospital of Larissa, Nikotsara 6, Larissa 41223, Greece. gregsurg@yahoo.gr

Telephone: +30-24-10239547 Fax: +30-24-10681170

Received: August 10, 2007 Revised: September 18, 2007

\begin{abstract}
Ectopic pancreas is defined as pancreatic tissue found outside the usual anatomic location of the pancreas. It is often an incidental finding and can be found at different sites in the gastrointestinal tract. It may become clinically evident when complicated by pathologic changes such as inflammation, bleeding, obstruction, and malignant transformation. In this report, a 40 years old woman with epigastric pain due to ectopic pancreatic tissue in the stomach is described. The difficulty of making an accurate diagnosis is highlighted. The patient has remained free of symptoms since she underwent wedge resection of the lesion three years ago. Frozen sections may help in deciding the extent of resection intraoperatively. Although ectopic pancreas is rare, it should be considered in the differential diagnosis of a submucosal gastric tumour.
\end{abstract}

(C) 2007 WJG. All rights reserved.

Key words: Ectopic pancreas; Stomach; Histology; Surgery

Christodoulidis G, Zacharoulis D, Barbanis S, Katsogridakis E, Hatzitheofilou K. Heterotopic pancreas in the stomach: A case report and literature review. World J Gastroenterol 2007; 13(45): 6098-6100

http://www.wjgnet.com/1007-9327/13/6098.asp

\section{INTRODUCTION}

Pancreatic heterotopia was first described in 1727 when it was found in an ileal diverticulum ${ }^{[1]}$. It is a rare entity, defined as the presence of extrahepatic tissue without any anatomic or vascular continuity with the pancreas. It may occur at a variety of sites in the gastrointestinal tract having a propensity to affect the stomach and small intestine. Usually, it is a silent anomaly but it may become clinically evident when complicated by inflammation, bleeding, obstruction or malignant transformation ${ }^{[2]}$. We report a case of a 40-year-old female with an ectopic pancreatic lesion in the antrum of the stomach.

\section{CASE REPORT}

A 40-year-old woman was admitted to our hospital due to a 2-mo history of recurrent episodes of epigastric pain, nausea and vomiting. Physical examination, routine blood tests including amylase, plain chest and abdominal $\mathrm{X}$ rays along with abdominal ultrasound were unremarkable. Esophagogastroduodenoscopy revealed a sessile polypoid mass with benign features located in the gastric antrum to the posterior wall measuring approximately $2 \mathrm{~cm}$ in diameter. The mucosa appeared normal throughout the stomach. Biopsy confirmed the presence of a normal gastric mucosa over the lesion. Computed tomography was not performed.

A decision was made to proceed with surgery. Endoscopic injection with methylene blue was performed to mark the lesion preoperatively.

The patient underwent exploratory laparotomy. Through a small midline incision a gastrotomy was performed. The lesion was clearly stained with methylene blue $4 \mathrm{~h}$ after the endoscopy. It was located approximately 10 $\mathrm{cm}$ from the pylorus to the greater curvature. In palpation the lesion was rubber like, fixed to the surrounding mucosa giving the feeling 'like a breast fibroadenoma'. Its dimension was approximately $5 \mathrm{~cm} \times 3 \mathrm{~cm} \times 4 \mathrm{~cm}$. By using a stapler device a wedge resection of the lesion was performed with macroscopically clear margins. Frozen sections excluded malignancy and the possibility of ectopic pancreatic lesion. The surgical margins were clear.

The patient had no postoperative complications and was discharged $4 \mathrm{~d}$ later. She has remained free of symptoms with negative endoscopy since then.

Histopathologic examination of the lesion showed heterotopic pancreatic tissue in the gastric antrum with a lobular architecture characteristic of ectopic pancreas. The pancreatic lobules were located mainly in the gastric submucosa (Figure 1A) and partially in the muscularis propia (Figure 1B). They contained a mixture of pancreatic acini, ducts and islets of Langerhans. The overlying gastric mucosa was normal.

\section{DISCUSSION}

Ectopic pancreas is defined as pancreatic tissue that lacks anatomical or vascular communication with the normal 

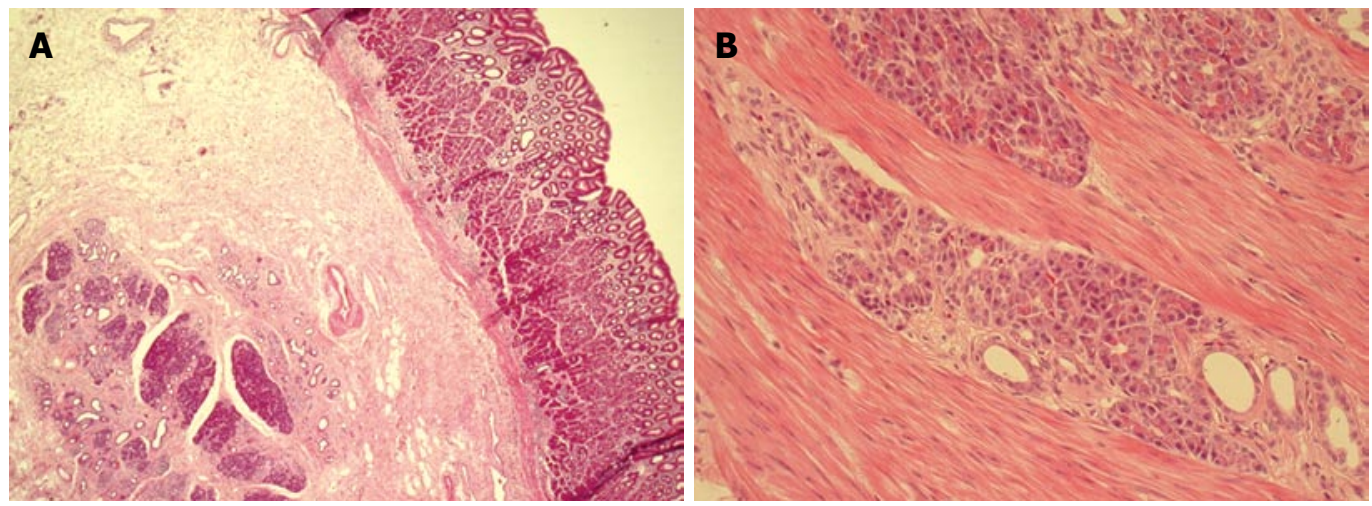

Figure 1 Heterotopic pancreatic lobules occupying the submucosa under an intact normal gastric mucosa ( $\mathrm{HE}, \mathrm{x}$ 100) (A) and between smooth muscle fibers of the gastric muscularis propria (HE, x 200) (B).

body of the pancreas ${ }^{[3]}$. Heterotopic pancreas has a genetic make-up, physiologic function, and local environmental exposure similar to that of the pancreas ${ }^{[4]}$. The incidence in autopsies ranges $0.5 \%-13.7 \%$, being more common at the age of 30-50 years with a male predominance ${ }^{[3]}$.

Of the 105 gastrectomies performed in our institution over the last five years, ectopic pancreatic tissue was found in only one case $(1 / 105,0.9 \%)$.

Several theories have been proposed to explain the pathogenesis and occurrence of pancreatic heterotopia. The most tenable theory implicates that during the development of normal pancreas from several evaginations, originating from the wall of the primitive duodenum, one or more evaginations may remain in the bowel wall. Migration of this embryonic remnant along with the development of the gastrointestinal tract gives rise to the ectopic pancreatic tissue $^{[5]}$. Another theory suggests that during embryogenesis pancreatic metaplasia of the endodermal tissues localized in the gastric submucosa may occur ${ }^{[5]}$.

Histopathologically, it is not a diagnostic problem when pancreatic acini, ducts, islets of Langerhans and intervening connective tissue are present. The most characteristic gross feature is a central ductal orifice ${ }^{[6]}$.

Specifically in the stomach, the involvement of submucosal layer, muscularis and subserosal layer is $73 \%, 17 \%$ and $10 \%$, respectively ${ }^{[7]}$. In the presented case the pancreatic tissue involved both the submucosa and muscularis propria. Heinrich in 1909 proposed three types of heterotopic pancreas but his classification was modified by Gaspar-Fuentes in 1973 acquiring its final form. Type I heterotopia consists of typical pancreatic tissue with acini, ducts, and islet cells similar to those seen in normal pancreas (Figure 1). Type II heterotopia is composed of pancreatic ducts only, referred as canalicular variety. Type III heterotopia is characterized by acinar tissue only (exocrine pancreas). Type IV heterotopia is made up of islet cells only (endocrine pancreas) ${ }^{[8]}$.

The usual location is in the stomach in $25 \%-38 \%$ of the cases, duodenum in 17\%-36\%, jejunum in $15 \%-21.7 \%$ and rare in the esophagus, gallbladder, common bile duct, spleen, mesentery, mediastinum and fallopian tubes. Gastric lesions are discovered in the antrum in $85 \%-95 \%$, either on the posterior or anterior wall, being more common along the greater curvature ${ }^{[5]}$.

The pancreatic ectopic tissue is usually silent but can also undergo complications that occur in normal pancreatic tissue such as acute or chronic pancreatitis, abscess and pseudocyst formation ${ }^{[9]}$. Malignant transformation may rarely occur. Up to 15 cases have been reported so far $^{[10]}$. In order to be described as arising from heterotopic pancreas, the diagnosis of a carcinoma should fulfil three criteria: (1) the tumour must be located within or very close to the ectopic pancreatic tissue, (2) transition between pancreatic structures and carcinoma must be identified and (3) the non-neoplastic pancreatic tissue must comprise fully developed acini and ducts ${ }^{[1]}$. Adenocarcinomas arising from ectopic pancreas seem to have a somewhat better prognosis than those arising from the pancreas itself, probably due to earlier presentation ${ }^{[10]}$.

Symptoms depending upon the anatomical location, such as gastric outlet obstruction in a pre-pyloric rest or obstructive jaundice in a bile duct focus, may originate from the mass effect of the tumour ${ }^{[12]}$ and are also related to the size of the lesion. Lesions greater than $1.5 \mathrm{~cm}$ in diameter are more likely to cause symptoms ${ }^{[12]}$. Pain is one of the most common symptoms. The possible explanation is that the pain is due to endrocrine and exocrine function of the heterotopic pancreatic tissue, and relates to the secretion of hormones and enzymes, being responsible for inflammation or chemical irritation of the involved tissues ${ }^{[13]}$. Haemorrhage due to mucosal erosion, ulcer formation and perforation especially localized in the small intestine have also been reported ${ }^{[12]}$.

Barium swallow study may show a typical image of a rounded filling defect with central indentation. The reported sensitivity and specificity are $87.5 \%$ and $71.4 \%$, respectively $^{[14]}$. Upper GI endoscopy can demonstrate a broad based umbilicated submucosal lesion. In the majority of cases, biopsies are superficial and non diagnostic. However, positive biopsies can establish the diagnosis ${ }^{[15]}$. Endoscopic ultrasonography has proven to be a useful adjunct in identification of pancreatic rests, localizing in the submucosa and ranging $0.5-2 \mathrm{~cm}$. The combination of endoscopic ultrasonography with fine-needle aspiration allows cytologic evaluation of submucosal gastrointestinal lesions, having a sensitivity ranging $80 \%-100 \%{ }^{[16,17]}$.

Computed tomography findings are usually non specific. However, multi-slice spiral CT with oral and portovenous phase IV contrast may demonstrate the lesion which enhances similarly with the normal pancreatic tissue. CT can localize lesions with normal pancreatic tissue but cannot distinguish ectopic pancreas from other submucosal tumors $^{[18,19]}$.

In our case, since neither CT nor endoscopic ultra- 
sonography was performed and the biopsy showed normal gastric mucosa, the diagnosis was made based on the benign endoscopic features of the lesion.

The diagnosis may be sometimes difficult intraoperatively due to the gross similarity of pancreatic heterotopia with gastrointestinal stromal tumour (GIST), gastrointestinal autonomic nerve tumour (GANT), carcinoid, lymphoma or even gastric carcinoma. If in doubt, frozen section is very helpful to establish the diagnosis intraoperatively and to avoid unnecessary extensive operations.

In conclusion, although pancreatic heterotopia is rare, it should be always considered in the differential diagnosis of extramucosal gastric lesions. Despite the development of modern diagnostic modalities, its diagnosis remains challenging. Surgical excision provides symptomatic relief and is recommended especially if diagnostic uncertainty remains. If in doubt, frozen section can help to avoid unnecessary radical operations.

\section{REFERENCES}

1 Elfving G, Hästbacka J. Pancreatic heterotopia and its clinical importance. Acta Chir Scand 1965; 130: 593-602

2 Cullen JJ, Weydert C, Hinkhouse MM, Ritchie J, Domann FE, Spitz D, Oberley LW. The role of manganese superoxide dismutase in the growth of pancreatic adenocarcinoma. Cancer Res 2003; 63: 1297-1303

3 Mulholland KC, Wallace WD, Epanomeritakis E, Hall SR. Pseudocyst formation in gastric ectopic pancreas. JOP 2004; 5: 498-501

4 Zhang L, Sanderson SO, Lloyd RV, Smyrk TC. Pancreatic intraepithelial neoplasia in heterotopic pancreas: evidence for the progression model of pancreatic ductal adenocarcinoma. Am J Surg Pathol 2007; 31: 1191-1195

5 Chandan VS, Wang W. Pancreatic heterotopia in the gastric antrum. Arch Pathol Lab Med 2004; 128: 111-112

6 Sabiston Textbook of Surgery: The Biological Basis of Modern Surgical Practice. 15th ed. In: Sabiston DC, editor. Philadelphia: WB Saunders Company, 1997: 872-873

7 DeBord JR, Majarakis JD, Nyhus LM. An unusual case of heterotopic pancreas of the stomach. Am J Surg 1981; 141 269-273

8 Gaspar Fuentes A, Campos Tarrech JM, Fernández Burgui JL, Castells Tejón E, Ruíz Rossello J, Gómez Pérez J, Armengol Miró J. Pancreatic ectopias. Rev Esp Enferm Apar Dig 1973; 39: 255-268

9 Kaneda M, Yano T, Yamamoto T, Suzuki T, Fujimori K, Itoh $\mathrm{H}$, Mizumoto R. Ectopic pancreas in the stomach presenting as an inflammatory abdominal mass. Am J Gastroenterol 1989; 84: 663-666

10 Eisenberger CF, Gocht A, Knoefel WT, Busch CB, Peiper M, Kutup A, Yekebas EF, Hosch SB, Lambrecht W, Izbicki JR. Heterotopic pancreas--clinical presentation and pathology with review of the literature. Hepatogastroenterology 2004; 51: 854-858

11 Emerson L, Layfield LJ, Rohr LR, Dayton MT. Adenocarcinoma arising in association with gastric heterotopic pancreas: A case report and review of the literature. J Surg Oncol 2004; 87: 53-57

12 Armstrong CP, King PM, Dixon JM, Macleod IB. The clinical significance of heterotopic pancreas in the gastrointestinal tract. Br J Surg 1981; 68: 384-387

13 Ormarsson OT, Gudmundsdottir I, Mårvik R. Diagnosis and treatment of gastric heterotopic pancreas. World J Surg 2006; 30: $1682-1689$

14 Nicolau A, Bruneton JN, Balu C, Aubanel D, Roux P. Radiologic study of aberrant pancreas of gastroduodenal topography. Apropos of 11 cases. J Radiol 1983; 64: 319-324

15 Osanai M, Miyokawa N, Tamaki T, Yonekawa M, Kawamura A, Sawada N. Adenocarcinoma arising in gastric heterotopic pancreas: clinicopathological and immunohistochemical study with genetic analysis of a case. Pathol Int 2001; 51: 549-554

16 Thoeni RF, Gedgaudas RK. Ectopic pancreas: usual and unusual features. Gastrointest Radiol 1980; 5: 37-42

17 Chak A, Canto MI, Rösch T, Dittler HJ, Hawes RH, Tio TL, Lightdale CJ, Boyce HW, Scheiman J, Carpenter SL, Van Dam J, Kochman ML, Sivak MV Jr. Endosonographic differentiation of benign and malignant stromal cell tumors. Gastrointest Endosc 1997; 45: 468-473

18 Rodriguez FJ, Abraham SC, Allen MS, Sebo TJ. Fine-needle aspiration cytology findings from a case of pancreatic heterotopia at the gastroesophageal junction. Diagn Cytopathol 2004; 31: 175-179

19 Cho JS, Shin KS, Kwon ST, Kim JW, Song CJ, Noh SM, Kang DY, Kim HY, Kang HK. Heterotopic pancreas in the stomach: CT findings. Radiology 2000; 217: 139-144

S- Editor Liu Y L- Editor Wang XL E- Editor Ma WH 